\title{
Mass Attenuation Coefficient of Soil Samples in Kurdistan Region of Iraq by Using Gamma Energy at $0.662 \mathrm{MeV}$
}

\author{
Hemn M. Salh", Diyaree O. Kakil, Hawbash H.Karim, Ari M. Hamad, Halgurd Q. Othman \\ Department of Physics, Faculty of Science \& Health, Koya University, Iraq
}

Copyright $(2016$ by authors, all rights reserved. Authors agree that this article remains permanently open access under the terms of the Creative Commons Attribution License 4.0 international License.

\begin{abstract}
Mass attenuation coefficient of various soil samples (density ranges between 2.22 and $2.3 \mathrm{gcm}^{-3}$ ) collected from three sites distributed in Kurdistan Region of Iraq land have been determined for gamma energy $0.662 \mathrm{MeV}$ using gamma spectrometry. The average mass attenuation coefficients for the studied samples were found to be $0.0487,0.0492$ and $0.0493 \mathrm{~cm}^{2} \mathrm{~g}^{-1}$. The results have shown that Fe content of the samples has a strong effect on the mass attenuation coefficient. In general, mass attenuation coefficients determined in this study can be used for determination of gamma emitters in any soil samples.
\end{abstract}

Keywords Linear and Mass, Attenuation, Coefficients

\section{Introduction}

The linear attenuation coefficient also called the narrow beam attenuation coefficient, is a quantity, which specifies the ability of an absorber to reduce the intensity of gamma rays as they pass through a material such as soil due to the interactions, which faces the incident gamma rays by the soil contents [1]. The soil has chemical properties as on its chemical compositions like $\mathrm{O}, \mathrm{Ca}, \mathrm{Si}, \mathrm{Fe}, \mathrm{Ca}, \mathrm{Mg}, \mathrm{K}$, etc. However, the variation of gamma attenuation coefficients with soil composition is negligible above $300 \mathrm{keV}$ up to $3 \mathrm{MeV}$ and large below $50 \mathrm{keV}$ [2-4]. Several studies have been conducted on the effects of different factors on the mass attenuation coefficients of soil. For instance Hubbel (1982) has published proper values of gamma attenuation coefficients in mixtures and compounds in the energy range of $1 \mathrm{keV}$ to $20 \mathrm{KeV}$. Also, the data attenuation coefficients for elements having an atomic number from 1-92 and for 48 more materials have been investigated by Hubbell and Sheltzer in 1995 [5,6]. The purpose of this study is to calculate gamma linear and mass attenuation coefficients by irradiation of soil samples of different chemical compositions. This method is useful for the study of properties of the soils in agriculture purposes. The linear and mass attenuation coefficients of soil samples will be determined for Cs137 gamma source. In general, the attenuation of gamma rays expressed by using exponential decay law:

$$
\mathrm{I}=\mathrm{Io} \exp ^{(-\mu)}
$$

Where Io is the number of particles of radiation counted during certain time without any absorber, I is the number counted during the same time with a thickness $\boldsymbol{L}$ of an absorber between the source of radiation and the detector and $\mu$ is the linear absorption coefficient.

According to Cerry and Duxbury (1998) [7]. This equation may be cast into the linear form:

$$
\begin{gathered}
\operatorname{Ln}\left(\frac{\mathrm{I}}{\mathrm{I}_{0}}\right)=\ln \left(\mathrm{e}^{-\mu \mathrm{L}}\right) \\
\operatorname{Ln} \frac{\mathrm{I}}{\mathrm{I}_{0}}=-\mu \mathrm{L} \\
\operatorname{Ln} \mathrm{I}-\ln \mathrm{I}_{0}=-\mu \mathrm{L} \\
\operatorname{Ln} \mathrm{I}=-\mu \mathrm{L}+\ln \mathrm{I}_{0}
\end{gathered}
$$

Where $\mu$ the slope of each linear graphs of thickness against Ln (measured counts).

Furthermore, the mass absorption coefficient $\mu \mathrm{m}$ is defined as,

$$
\mu_{\mathrm{m}}=\mu / \rho
$$

Where, $\mu$ is measured in $\mathrm{cm}^{-1}, \mu_{\mathrm{m}}$ is measured in $\mathrm{cm}^{2} / \mathrm{gm}$ and $\rho$ is mass density of soil sample in $\mathrm{gm} / \mathrm{cm}^{3}[8-13]$.

\section{Experimental Setup}

For this work, soil samples were collected from south of Erbil province, east of Koya district and west of 
Chamchamal district in Kurdistan region of Iraq. The soils were in powder form, and then they pressed and converted into the pellet form with thicknesses about $1(\mathrm{~cm})$. After that, the chemical composition of a soil sample from each region is identified by using X-ray Fluorescence technique (XRF) at Solid State Physics Laboratory-Koya University. Then, the whole system was setup as shown in figure (1) below:

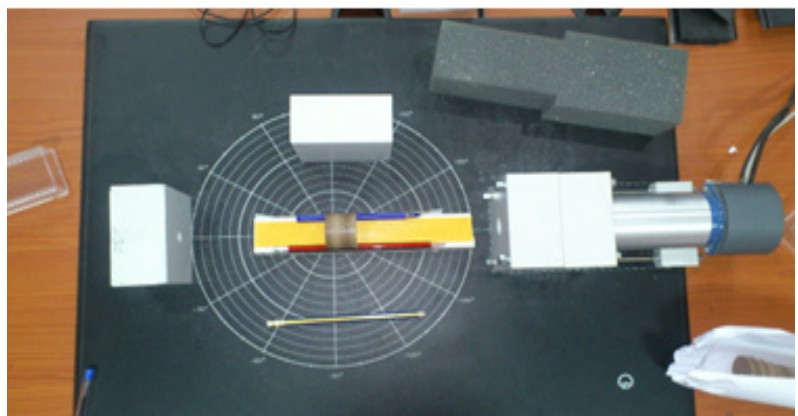

Figure 1. Experimental setup

For this experiment, Cassy Lab software was used to record data. Firstly the background radiation was measured: the number of counts Io of gamma without any absorber for 600 seconds to remove error due to random nature of radioactivity. Then, a soil sample with $1(\mathrm{~cm})$ thickness was put in between the detector and the gamma source as can be seen from the figure (1) for a certain time (600s) the number of counts I of gamma was measured. This step was repeated for different thicknesses of soil in each region and the soils of three mentioned regions. Furthermore, the graphs of thickness of soil sample (Path length) Versus Ln (gamma intensity I) for soil samples are plotted and shown in the next sections. Finally, slopes are noted for each straight line for the calculation of linear and mass attenuation coefficients.

\section{Results and Discussion}

a- The chemical composition of soils in each region is given in tables below:
Table 1. Main chemical components (\%mass) of the west of Chamchamal soil sample.

\begin{tabular}{|c|c|}
\hline Elements & Mass \% \\
\hline $\mathrm{O}$ & 44.5 \\
\hline $\mathrm{Si}$ & 20.5 \\
\hline $\mathrm{Ca}$ & 20.2 \\
\hline $\mathrm{Al}$ & 6.45 \\
\hline $\mathrm{Fe}$ & 3.6 \\
\hline $\mathrm{Mg}$ & 2.36 \\
\hline $\mathrm{K}$ & 1.18 \\
\hline $\mathrm{Ti}$ & 0.455 \\
\hline $\mathrm{Mn}$ & 0.0903 \\
\hline
\end{tabular}

Table 2. Main chemical components (\%mass) of the east of Koya soil sample.

\begin{tabular}{|c|c|}
\hline Elements & Mass\% \\
\hline $\mathrm{O}$ & 40.4 \\
\hline $\mathrm{Si}$ & 26.8 \\
\hline $\mathrm{Ca}$ & 12.7 \\
\hline $\mathrm{Al}$ & 9.61 \\
\hline $\mathrm{Fe}$ & 5.27 \\
\hline $\mathrm{Mg}$ & 2.4 \\
\hline $\mathrm{K}$ & 1.8 \\
\hline $\mathrm{Ti}$ & 0.598 \\
\hline $\mathrm{Mn}$ & 0.116 \\
\hline
\end{tabular}

Table 3. Main chemical components (\%mass) of the south of Erbil soil sample.

\begin{tabular}{|c|c|}
\hline Elements & Mass\% \\
\hline $\mathrm{O}$ & 44.2 \\
\hline $\mathrm{Ca}$ & 20.8 \\
\hline $\mathrm{Si}$ & 20.2 \\
\hline $\mathrm{Al}$ & 6.30 \\
\hline $\mathrm{Fe}$ & 3.70 \\
\hline $\mathrm{Mg}$ & 2.75 \\
\hline $\mathrm{K}$ & 1.19 \\
\hline $\mathrm{Ti}$ & 0.448 \\
\hline $\mathrm{Mn}$ & 0.0843 \\
\hline
\end{tabular}

b- Thickness $(\mathrm{cm})$ of soil samples versus Ln measured intensity (I) of gamma rays are shown graphically as follows: 


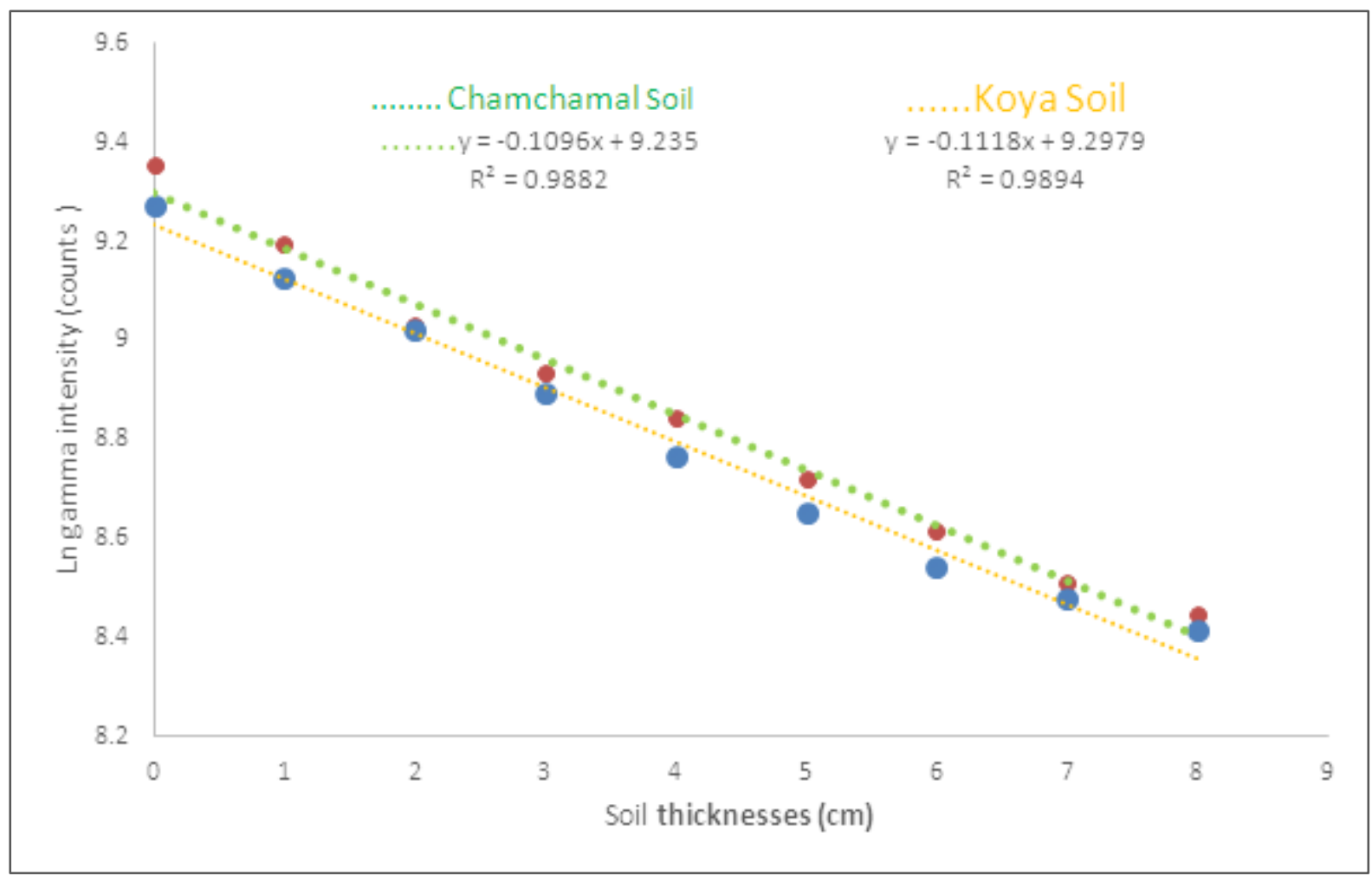

Figure 2. The thickness (cm) vs. Ln gamma intensity (counts)

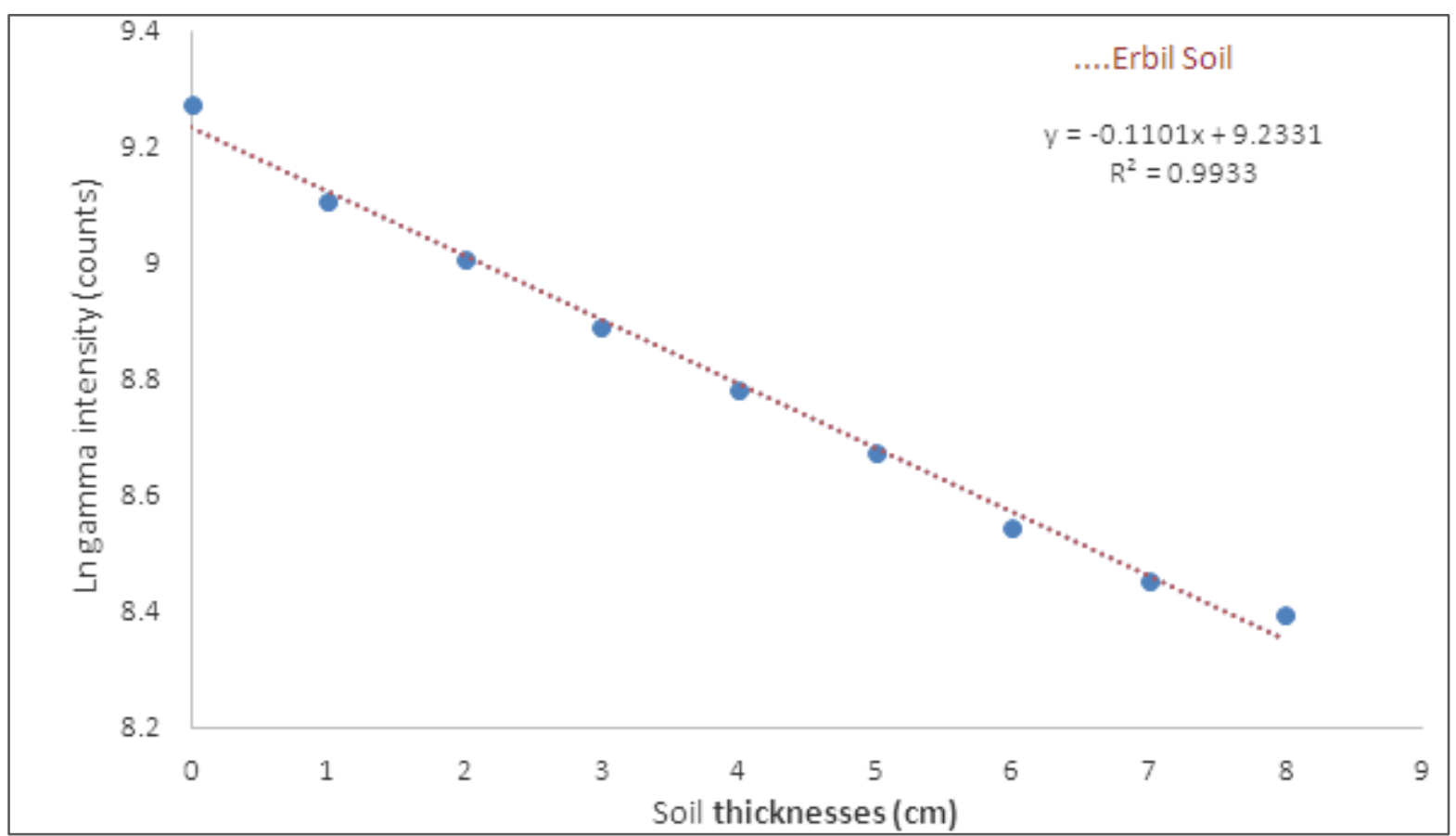

Figure 3. The thickness (cm) vs. Ln gamma intensity (counts)

\section{Discussion and Conclusion}

From the slope of the figures ( 2 and 3 ) and according to the equation (5) it was found that the linear attenuation coefficient of soil in the east of Koya district, west of Chamchamal district and south of Erbil province are $0.1118 \mathrm{~cm}^{-1}, \quad 0.1096 \mathrm{~cm}^{-1}$ and $0.1101 \mathrm{~cm}^{-1}$ respectively.
Moreover, from these values and the equation (6) the mass attenuation coefficients of soil in the east of Koya district $\left(2.2955 \mathrm{gcm}^{-3}\right)$, west of Chamchamal district $\left(2.2258 \mathrm{gcm}^{-3}\right)$, and south of Erbil province $\left(2.2311 \mathrm{gcm}^{-3}\right)$ are $0.0487 \mathrm{~cm}^{2} / \mathrm{gm}$, $0.0492 \mathrm{~cm}^{2} / \mathrm{gm}$, and $0.0493 \mathrm{~cm}^{2} / \mathrm{gm}$ respectively. It was observed that the experimental values of $\mathrm{Ln}$ gamma intensity counted were linearly decreased with increasing 
thickness. Also, as the density of soil increases, mass attenuation coefficient decreases exponentially. This confirms the contributions of photoelectric absorption, Compton scattering and pair production to the absorption of gamma rays by the soil samples.

\section{Conclusions}

The effect and chemical components like $\mathrm{C}, \mathrm{K}, \mathrm{S}, \mathrm{P}, \mathrm{Ca}$, $\mathrm{Na}, \mathrm{Mg}, \mathrm{Cu}, \mathrm{Fe}, \mathrm{Zn}$, etc. of soil samples on linear and mass attenuation coefficient have been studied at gamma ray energy $0.662 \mathrm{MeV}$. These attenuation coefficients usually depend on the energy of the incident radiation and the composition of the soil samples. Also, it can be concluded that from the previous tables, the $(\mathrm{Fe})$ content in soil has a significant effect on the values of attenuation coefficients.

\section{REFERENCES}

[1] L' Annunziata, M.F., (2004). Handbook of Radioactivity Analysis, second ed. Academic Press, Amsterdam.

[2] Raje D.V. and Chaudhari L.M. (2010) Mass attenuation coefficients of soil samples in Maharashtra State (India) by using gamma energy at $0.662 \mathrm{MeV}$, Bulg. J. Phys., 37, $158-164$

[3] Chaudhari Laxman M. and Raje Dayanand V. (2012)Study of photon attenuation coefficient of soil samples from Maharashtra and Karnataka states (India) from $122 \mathrm{keV}$ to $1330 \mathrm{keV}$., Research Journal of Chemical Sciences, 2(2)

[4] Demir D. Ozgul A. Un.M. and Sachin Y. (2008) Determination of Photon Attenuation Coefficient, Porocity and field capacity of soil by gamma ray transmission for 60 , 356 and $662 \mathrm{keV}$ gamma rays, Applied Radiation and Isotopes, 66, 1834-1837
[5] Hubbell J.H., Photon mass attenuation and energy absorption coefficients from $1 \mathrm{keV}$ to $20 \mathrm{keV}$, Appli. Radiat. Isot., 33, 1269 (1982)

[6] Hubbel J.H. and Sheltzer S.M. (1995) Tables of X-ray mass attenuation coefficient and mass energy absorption coefficients $1 \mathrm{keV}$ to $230 \mathrm{MeV}$ for elements $\mathrm{z}=1$ to 92 and 48 additional substances of dosimetric interest, NISTIR-5632

[7] Cerry, P., and Duxbury, A.M (1998) Practical Radiotherapy: Physics and Equipment. Cambridge University Press.

[8] Bradley D.D., Chong C.S., Shukri A., Tajuddin A.A. and Ghose A.M. (1989) A new method for the direct measurement of the energy absorption coefficient of gamma rays, Nucl. Instrum. Meth.Phys. Res., A280, 39

[9] Jahagirdar H.A., Hanumaiah B. and Thontadarya B.R. (1992) Determination of narrow beam attenuation coefficients from broad beam geometrical configuration for $320 \mathrm{KeV}$ photons, Int., Appli.Radiat .Isot, 43, 1511

[10] Teli M.T., Chaudhari L.M. (1996) Linear attenuation coefficient of gamma radiation in dilute solutions of potassium chloride, Appli. Radiat. Isot., 47, 365

[11] Bhandal G.S. (1994) Study of Photon attenuation coefficients of some multielement materials, Nuclear Science and Engineering, 116, 218-222

[12] Cunningham J.R. and Johns H.E. (1980) Calculation of the average energy absorbed in photon interactions, Med.Phys,7, 51

[13] Carlsson G.A. (1981) Absorbed Dose Equations, On the Derivation of a General Absorbed Dose Equation and Equations Valid for Different Kinds of Radiation Equilibrium, Radiation Research, 5, 219-237

[14] Singh K., Bal H.K., Sohal I.K. and sud S.P. (1991) Measurement of absorption coefficients at $662 \mathrm{keV}$ in soil samples, Applied Radiation Isotop, 42, 123 